\title{
Unknown syndrome: mental retardation with dysmorphic features, early balding, patella luxations, acromicria, and hypogonadism
}

\author{
F A Scholte, J H Begeer, A J van Essen
}

\begin{abstract}
A patient is described with severe mental retardation, a peculiar face with small palpebral fissures and premature balding, habitual patella luxations, small hands and feet, and hypogonadism, a combination which appears to represent a new syndrome.
\end{abstract}

\section{History}

The proband is a 25 year old male, born at 36 weeks' gestation with a birth weight of $2150 \mathrm{~g}$. He is the youngest of four sons of non-consanguineous parents. Two years before his birth the mother had a miscarriage. The family history was negative for mental retardation. At his birth the mother was 43 and the father 48 years old. The pregnancy was complicated by vaginal blood loss at two months, which was treated with allylestrenol, and maternal cystitis in the fifth month, which was treated with nitrofurantoin.

The psychomotor development of our patient was slow. He slept most of the time for the first six months. He stood with support at 2 years and walked independently at 4 years. Dental eruption started.at 16 months. He had habitual patella luxations and pes

Mariëncamp, Institute for Mentally Retarded People, PO Box 8, 9450 AA Rolde, The Netherlands.

F A Scholte

Department of Child Neurology, University Hospital, PO Box 30001, 9700 RB Groningen, The Netherlands. J H Begeer

Department of Medical Genetics, University Hospital, PO Box 30001, 9700 RB Groningen, The Netherlands. A J van Essen

Correspondence to Dr Scholte.

Received for publication 19 March 1990.

Revised version accepted for publication 14 September 1990. cavus for which he was operated upon at the age of 7 and 10 years, respectively.

\section{Clinical examination}

The patient is an anxious young man who is unable to speak. His height is $1.65 \mathrm{~m}$ (below the 10th centile) and his weight is $63 \mathrm{~kg}$ (50th centile). The head circumference is $54 \mathrm{~cm}$ (10th centile). The cranium is narrow with a flat occiput. The forehead is high and globular. Low positioned, deep temporal inlets ('Geheimratsecken') and early frontal balding which started before the age of 14 years are noticeable. His irides are pale blue. The eyes have upward slanting palpebral fissures and medial epicanthic folds. The ICD is $3.4 \mathrm{~cm}$ (75th centile), the OCD $8.0 \mathrm{~cm}$ (between the 3rd and 25th centile), and the IPD $5.7 \mathrm{~cm}$ (50th centile). The palpebral fissures look small $(2.3 \mathrm{~cm})$. The nose is small and has a bulbous tip. The protruding right ear has a flattened anthelix. The upper lip is thin and the philtrum short. The palate is high arched (figs 1, 2, and 3). The hands and feet are small (right hand $14.4 \mathrm{~cm}$ and left hand $15.9 \mathrm{~cm}$, below 3rd centile; feet $20 \mathrm{~cm}$, well below 3 rd centile). Flexion in the metacarpophalangeal joints of the second, third, and fourth fingers of both hands is limited, and the proximal interphalangeal joints of both hands are hyperextensible. Slight syndactyly of the second and third and of the fourth and fifth toe was noted. The spine shows kypholordosis. A large café au lait spot is present on the right side of his abdomen. Mild truncal obesity is apparent.

The penis and testes are small (both $3.5 \mathrm{~cm}$ ), but body hair distribution shows a normal male pattern. Neurological examination showed slight hypotonia, an unsteady gait, and a mild pyramidal syndrome of the legs. There is no evidence of dysfunction of the internal organ systems. 


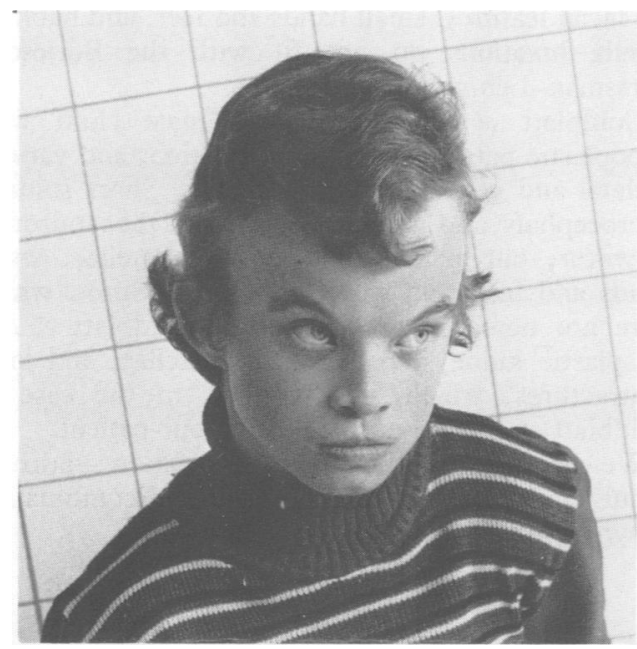

Figure 1 The patient at the age of 14 years showing early frontal balding and facial peculiarities.

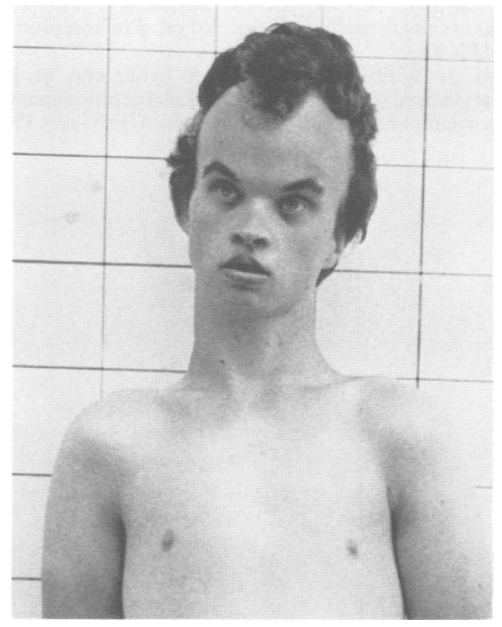

Figure 2 The patient at 17 years showing more pronounced frontal balding.

\section{Investigations}

Routine haematology, blood chemistry, and metabolic screen gave normal results. Tests for syphilis and toxoplasmosis were negative. The cerebrospinal fluid showed normal levels of lactate and pyruvate and there were no further abnormalities. Chromosomal analysis showed a normal male karyotype (GTG banding at approximately the 600 band level). No fragile $\mathrm{X}$ chromosomes were found in 50 metaphases. As a small balanced translocation can sometimes be found more easily than the unbalanced state, we examined the chromosomes of our patient's parents.
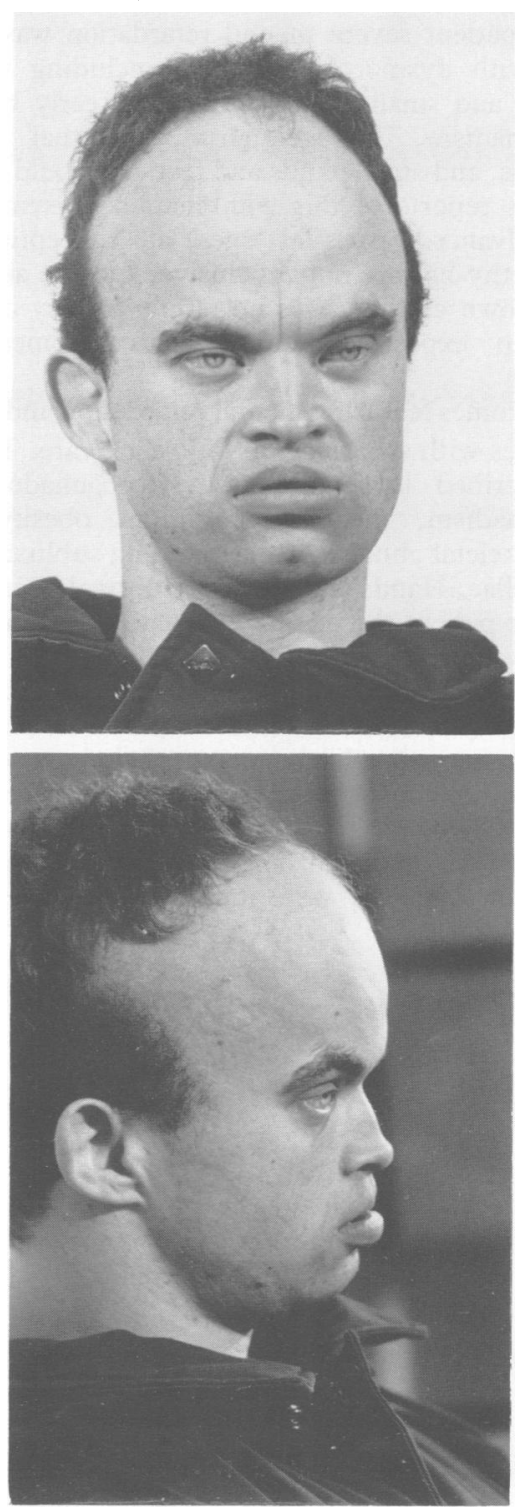

Figure $3 A P$ and lateral view of the patient at 25 years.

They too had normal karyotypes (also with GTG banding at approximately the 600 band level). Electroencephalographic examination was normal. $X$ rays of the knees showed narrow epiphyses with slight degenerative changes and normal patellae. $X$ ray examinations of the skull, the thorax, and the hands were unremarkable. Apart from a small area of hypodensity around the frontal horns, the CT scan of the brain showed no convincing abnormalities. 


\section{Discussion}

In our patient severe mental retardation was found along with dysmorphic features including upward slanting and small palpebral fissures, early balding, hypogonadism, hypogenitalism, habitual patella luxations, and small hands and feet. We could find no previous reports of this combination of symptoms. The advanced parental ages at conception are noteworthy but are not conclusive, and the aetiology is unknown as there was no family history or overt teratogen exposure and the chromosomes were normal.

Syndromes featuring mental retardation and patella anomalies with a normal karyotype are rare. Teebi $e t$ $a l^{1}$ described three sibs with hypogonadotrophic hypogonadism, mental retardation, obesity, and minor skeletal abnormalities including subluxation of the patellae. Hands and feet were normal. Compared with our patient the mental retardation was mild and frank dysmorphic features were lacking.

The $\mathrm{X}$ linked Börjeson-Forssman-Lehmann syndrome $^{2}$ consists of severe mental retardation, epilepsy, hypogonadism, microcephaly, coarse facies with prominent supraorbital ridges, deep set eyes, large ears, and obesity. Variable skeletal abnormalities are found in this syndrome. Mental deficiency and mild truncal obesity were found in our patient, but the facial features, small hands and feet, and habitual patella luxations do not fit with the BörjesonForssman-Lehmann syndrome.

Goldblatt et $a l^{3}$ described a male child with hypoplastic patellae, mental retardation, and various skeletal and genitourinary anomalies. Short stature, microcephaly, and large ears were part of the syndrome. However, our patient had normal patellae, small hands and feet, and short palpebral fissures, which were not noted in the patient of Goldblatt et $a l^{3}{ }^{3}$ Dysplastic kidneys, rudimentary patellae, and joint contractures, which were evident in the case of Goldblatt $e t a l,{ }^{3}$ were not found in our patient.

We conclude that the mental retardation syndrome of our patient seems to represent a unique combination of symptoms.

1 Teebi AS, Al-Awadi SA, Talaat JF, Naguib KK. Hypogonadotropic hypogonadism, mental retardation, obesity, and minor skeletal abnormalities: another new autosomal recessive syndrome from the Middle East. Am f Med Genet 1986;24: 373-8.

2 Smith DW. Börjeson-Forssman-Lehmann syndrome, large ears, hypogonadism, severe mental deficiency. In: Recognizable patterns of human malformations. 3rd ed. Philadelphia: Saunders, patterns of hum $1982: 438-9$.

3 Goldblatt J, Wallis C, Zieff S. A syndrome of hypoplastic patellae, mental retardation, skeletal and genitourinary anomalies with normal chromosomes. Dysmorphol Clin Genet 1988;2:91-3. 